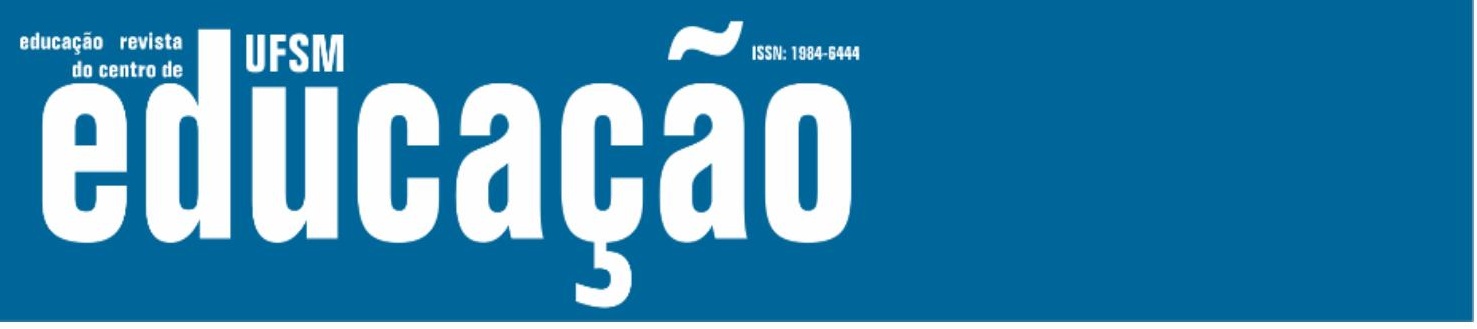

ISSN: 1984-6444 | http://dx.doi.org/10.5902/1984644445309

\title{
Currículo de formação docente inicial e inclusão de estudantes PAEE: uma análise do Projeto Imersão Docente
}

\author{
Curriculum of pre-service teacher education and inclusion of PAEE \\ students: an analysis of the Projeto Imersão Docente
}

\begin{abstract}
Maria Carolina da Silva Caldeira
Professora doutora da Universidade Federal de Minas Gerais, Belo Horizonte, Minas Gerais, Brasil. mariacarolinasilva@hotmail.com - https://orcid.org/0000-0003-0668-1989
\end{abstract}

Recebido em 01 de junho de 2020

Aprovado em 07 de janeiro de 2021

Publicado em 30 de junho de 2021

\section{RESUMO}

Este artigo analisa os saberes e as práticas disponibilizados no currículo de formação inicial docente do Projeto Imersão Docente (PID), no que se refere à inclusão de estudantes público-alvo da educação especial (PAEE), com base nos significados atribuídos por aqueles/as que participaram do Projeto. O PID constituise como uma possibilidade de formação inicial de professores/as que opera por meio da inserção de futuros/as docentes em turmas de ensino fundamental de uma escola de tempo integral que funciona em uma Universidade Federal. Nesse Projeto, os/as estudantes de graduação têm a possibilidade de atuarem como mediadores/as do processo de inclusão de alunos/as PAEE, sendo orientados/as pela equipe docente que atua na instituição. Com base na perspectiva pós-crítica e, particularmente, nos conceitos desenvolvidos por Michel Foucault, compreende-se que o currículo desse Projeto disponibiliza certos saberes e demanda que os/as graduandos/as exerçam certas práticas sobre si mesmos/as a fim de constituírem-se como futuros/as professores/as que tomam a inclusão como aspecto central de suas ações docentes. Por meio da análise de entrevistas realizadas com treze graduandos/as que atuaram no Projeto entre 2016 e 2018, argumenta-se que esse currículo opera com saberes que proporcionam o questionar(-se) constante, a compreensão da "diferença dentro da diferença" e a crença no potencial de todos/as para a permanente aprendizagem. Dessa forma, esse currículo reativa o imperativo da inclusão que opera na atualidade e produz docentes que acreditam na potencialidade da educação inclusiva para a promoção de uma educação mais justa e igualitária.

Palavras-chave: Currículo; Educação inclusiva; formação de professores. 


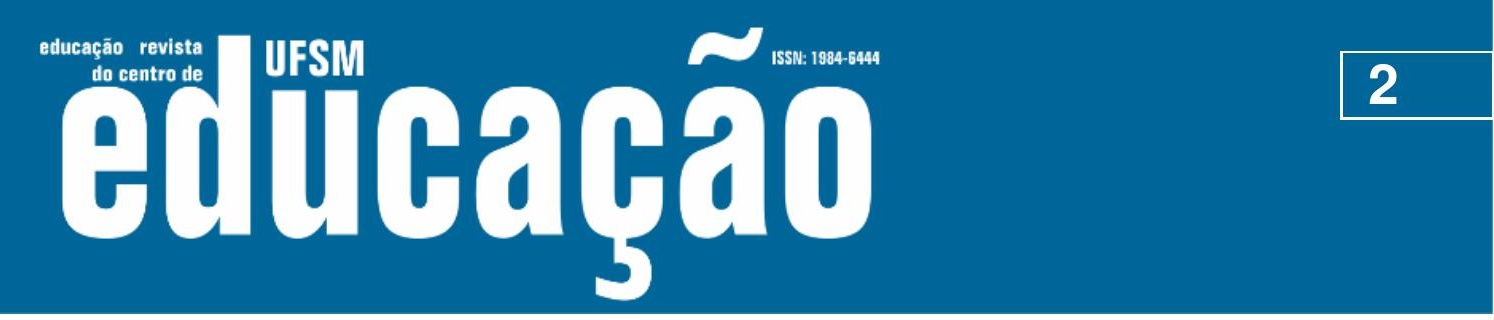

ISSN: 1984-6444 | http://dx.doi.org/10.5902/1984644445309

\section{ABSTRACT}

This article analyzes the knowledge and practices made available in pre-service teacher education curriculum of the Projeto Imersão Docente (PID) with regard to the inclusion of students targeting special education (PAEE), based on the meanings attributed by those who participated in the Project. The PID constitutes a possibility of pre-service teacher education that operates through the insertion of future teachers in elementary school classes at a full-time school that works at a Federal University. In this Project, undergraduate students have the possibility to act as mediators for the process of inclusion of students PAEE, being guided by the teaching team that works at the institution. Based on the post-critical perspective and, particularly, on the concepts developed by Michel Foucault, it is understood that the curriculum of this Project provides certain knowledge and demands that undergraduate students exercise certain practices on themselves in order to constitute as future teachers who take inclusion as a central aspect of their teaching actions. Through the analysis of interviews conducted with thirteen undergraduate students who worked on the Project between 2016 and 2018, it is argued that this curriculum operates with knowledge that provides constant questioning (if), the understanding of "difference within difference" and the belief in everyone's potential for permanent learning. Thus, this curriculum reactivates the imperative of inclusion that operates today and produces teachers who believe in the potential of inclusive education to promote a more just and equal education.

Keywords: Curriculum; Inclusive education; Teacher education.

\section{Introdução}

A enunciação "eu não estou preparado/a para lidar com estudantes com deficiência" é recorrentemente acionada por docentes da educação regular e aparece em diferentes estudos sobre a educação especial na perspectiva inclusiva no Brasil (MANTOAN, 2009; ORRU, 2019). Repetida por professores/as que, na maioria das vezes, tiveram pouco ou nenhum contato com discussões teóricas ou com experiências práticas voltadas à inclusão durante sua formação inicial, ela expressa uma das questões que tem se colocado ao campo da formação docente na contemporaneidade, qual seja, como formar os/as docentes para lidar com a diferença no contexto escolar. Essa também vem sendo uma questão colocada pelo campo curricular, que tem debatido como escutar "o que os diferentes têm a dizer e 


\section{Autนaดูลิ}

ISSN: 1984-6444 | http://dx.doi.org/10.5902/1984644445309

si referem-se "a processos pelos quais o indivíduo age sobre si próprio" (FOUCAULT, 1993, p. 207) de maneira a conduzir-se de dada maneira.

$O$ argumento que defendo, neste artigo, é o de que esse currículo opera com saberes que proporcionam o questionar(-se) constantemente, a compreensão da diferença dentro da diferença e a crença no potencial de todos/as para aprenderem permanentemente, a fim de produzir sujeitos professores/as que acreditam na potencialidade da educação inclusiva. Nesse sentido, o imperativo da inclusão é reativado nesse currículo, contribuindo para a cadeia discursiva que coloca a presença na escola regular como um direito dos/as educandos/as PAEE. Para desenvolvimento desse argumento, este artigo está dividido em quatro partes, além desta introdução. Na primeira delas, apresento os elementos teóricos que subsidiam a análise realizada, desenvolvendo os conceitos de currículo, saberes, práticas de si e imperativo da inclusão. Na segunda, contextualizo mais detidamente a escola em que o PID desenvolve-se, a metodologia utilizada e o perfil dos/as graduandos/as que participaram das entrevistas. Na terceira, analiso as três práticas de si que considero constituintes desse currículo e os saberes nelas envolvidos. Por fim, apresento as considerações finais do trabalho, apontando alguns ensinamentos que esse currículo pode nos trazer para pensarmos a formação docente inicial na perspectiva da educação inclusiva.

\section{Currículo, práticas de si e imperativo da inclusão: ferramentas teóricas para compreender o Projeto Imersão Docente}

As práticas relativas à inclusão de estudantes com deficiência, transtornos globais de desenvolvimento e altas habilidades/superdotação têm demandado a reestruturação dos currículos das escolas de diferentes níveis. Isso fica evidente no artigo 59 da LDBEN 9394/1996, Inciso I, que determina que os sistemas de ensino deverão assegurar aos educandos PAEE "currículos, métodos, técnicas, recursos educativos e organização específicos, para atender às suas necessidades" (BRASIL, 1996). De maneira semelhante, essas práticas têm também demandado a reestruturação dos currículos de formação docente, já que é necessário garantir 


\section{تilloapão}

ISSN: 1984-6444 | http://dx.doi.org/10.5902/1984644445309

"professores com especialização adequada em nível médio ou superior, para atendimento especializado, bem como professores do ensino regular capacitados para a integração desses educandos nas classes comuns" (BRASIL, 1996). Para isso, os cursos de formação inicial de professores/as para a educação básica deveriam "incluir, em seus currículos, 'conteúdos sobre educação especial"” (KASSAR, 2014, p. 210). Entretanto, diferentes análises têm demonstrado que essa "capacitação"3 não ocorreu.

Porém, não é desde a perspectiva da reestruturação curricular dos cursos superiores de formação docente que me proponho a pensar o currículo. Meu objetivo aqui é problematizar que sujeito é demandado por um currículo que atua na formação de professores/as. Cabe registrar que currículo não se restringe a uma matriz, na qual estão dispostos os saberes e conhecimentos a serem construídos em determinado período de escolarização. O currículo envolve uma determinada forma de organizar saberes, conhecimentos e práticas, para produzir um tipo de sujeito (SILVA, 1995).

A pesquisa que dá base a este artigo insere-se no campo de estudos e pesquisas pós-críticos em educação e, particularmente, utiliza os conceitos de Michel Foucault para pensar o currículo e a formação docente. Especificamente, procuro analisar os saberes e as práticas de si considerados como fundamentais pelos/as graduandos/as que vivenciaram esse currículo para a sua formação como futuros/as professores/as. Não se trata, portanto, de investigar as práticas que foram desenvolvidas junto aos/às estudantes PAEE ou de analisar os modos como esses/as futuros/as docentes atuavam. Trata-se de procurar entender como a possibilidade de atuar junto aos/às estudantes em uma escola de ensino fundamental ensinou determinados modos de ser docente para esses/as graduandos/as. Nessa perspectiva, o currículo vivenciado por eles/as junto aos/às estudantes do ensino fundamental e significado nas entrevistas é entendido como uma "prática subjetivadora" (CORAZZA, 2001, p. 57).

A subjetivação, nessa perspectiva, não se refere a uma subjetividade interior e essencial. Ela é produzida em meio a relações de poder-saber e técnicas de si. Foucault (1998), ao longo de seus estudos, procurou mostrar como os indivíduos 


\section{Authaดูã}

ISSN: 1984-6444 | http://dx.doi.org/10.5902/1984644445309

eventualmente fiquem de fora, não fazendo parte do conjunto dos cidadãos, não podem ser governados" (CARVALHO; GALLO, 2020, p. 152).

A inclusão faz parte, portanto, de uma estratégia de Estado que aciona relações específicas de poder para produzir a inserção de todos/as na lógica capitalista, já que, nesse momento histórico, não pode haver indivíduos completamente excluídos dos diferentes processos sociais. Eles/as precisam viver em um processo ambíguo e volátil de in/exclusão (LOPES; FABRIS, 2017), processo esse que está envolvido em relações de poder que marcam os limites e as normas para estar ou não incluído/a. A lógica da in/exclusão parte do princípio de que o "jogo formal de desigualdades do neoliberalismo, não garante condições de igualdade entre os sujeitos" (LOCKMAN, 2020, p. 69), o que faz com que as formas de in/exclusão sejam vividas de maneiras diferentes por indivíduos distintos. Apesar desses "gradientes de inclusão", Lockman (2020, p. 69) afirma que, ao longo da última década, "considerando o contexto brasileiro, a inclusão se constituiu em um imperativo de Estado".

Cabe registrar, todavia, que após o rompimento da democracia institucional no Brasil, "desde 2016 emergiu uma enunciação visando a combater as experiências e as teorias educativas voltadas para as diferenças e as políticas afirmativas de inclusão social" (CARVALHO; GALLO 2020, p. 147). Nesse sentido, o momento atual é de tensão em torno da inclusão como um imperativo, já que práticas têm sido desenvolvidas "nessa governamentalidade neoliberal conservadora, [para] constituir um novo direito: o direito à exclusão" (LOCKMAN, 2020, pp. 72-73). Todavia, no contexto do currículo investigado, a inclusão apresenta-se como um imperativo, no sentido de que se busca que os/as estudantes estejam incluídos nas práticas escolares desenvolvidas, bem como se demanda uma subjetividade inclusiva por parte dos/as graduandos/as. Eles/as são, então, inseridos em relações de poder que visam à sua constituição como sujeitos inclusivos.

Na perspectiva foucaultiana, o poder - mesmo em uma análise de Estado não é exclusivamente repressivo ou de mão única. Ele não deve ser compreendido como "um fenômeno de dominação maciço e homogêneo de um indivíduo sobre os outros, de um grupo sobre os outros, de uma classe sobre as outras" (FOUCAULT, 
ISSN: 1984-6444 | http://dx.doi.org/10.5902/1984644445309

\section{Caracterização do Projeto Imersão Docente e dos/as graduandos/as entrevistados/as}

Experiências de formação docente que envolvem a formação prática de professores/as em escolas de educação básica vêm sendo propostas no Brasil desde o início deste século. De acordo com Faria e Diniz-Pereira (2019), muitas dessas experiências inspiram-se na ideia de residência médica, segundo a qual, imediatamente após o período de formação acadêmica, o/a profissional deve ter uma profunda inserção no ambiente prático, junto com profissionais mais experientes. Essa ideia vem sendo apropriada no campo educacional e resultou em Projetos de Lei e propostas de formação em instituições de ensino superior tanto para a formação docente inicial como para a formação continuada.

O Projeto aqui analisado tem sua história articulada ao reconhecimento da importância da inserção na prática escolar como aspecto importante para a formação docente. Criado em 2011 pela equipe do CAp, o Projeto era nomeado inicialmente como Residência Docente e, a partir de 2013, tem seu nome alterado para Projeto Imersão Docente (PID). Na proposta do PID, os/as graduandos/as de diferentes licenciaturas da Universidade a qual o Colégio de Aplicação é vinculado atuam com estudantes do $1^{\text {을 }}$ ao $9^{\circ}$ ano do ensino fundamental, sendo orientados/as por professores/as da instituição. Além disso, o PID conta com uma equipe de formação que realiza encontros semanais com os/as graduandos/as, nos quais são debatidos temas relativos à educação.

O ingresso para estudantes no referido CAp é feito anualmente por meio de sorteio público de 50 vagas para o $1^{\circ}$ ano do ensino fundamental. Desde $2016,5 \%$ dessas vagas são destinadas a estudantes com deficiência, o que significa que, em cada ano escolar, haverá, pelo menos, três alunos/as PAEE. Os/as estudantes com deficiência também podem concorrer nas vagas de ampla concorrência, o que faz com que esse número possa ser maior do que três crianças por ano escolar. Em 2019, o CAp contava com cerca de 450 estudantes, sendo que desses 19 tinham alguma deficiência. Alguns/algumas desses estudantes necessitavam de apoio e mediação nas tarefas escolares. Por causa disso, o PID destinava algumas de suas 


\section{Autนaดูลิ}

ISSN: 1984-6444 | http://dx.doi.org/10.5902/1984644445309

bolsas para que graduandos/as pudessem acompanhar esses/as estudantes no cotidiano escolar, realizando o processo de mediação entre eles/as e diferentes aspectos da vida escolar.

A pesquisa que subsidia este artigo entrevistou, no ano de 2018, 13 graduandos/as que atuaram como mediadores/as no PID. O instrumento utilizado foi a entrevista narrativa, uma técnica para produção de informações de pesquisa por meio de uma conversa, a partir de alguns eixos estruturantes, para compreender os sentidos e significados atribuídos pelos/as entrevistados/as a determinadas situações vividas (ANDRADE, 2008). Nesse sentido, "a narrativa, ao ordenar e atribuir sentidos aos acontecimentos, articulando-os em uma seqüência temporal significativa, permite ao/a narrador/a a elaboração de imagens de si, do outro e do mundo e a atribuição de significados às suas experiências" (PÁDUA; TEIXEIRA, 2006, p. 3). A entrevista pode ser considerada como uma instância que "traz informações fundamentais acerca do vivido e possibilita uma interpretação (mesmo que provisória e parcial)" (ANDRADE, 2008, p. 175) daquilo que foi vivenciado. Os/as graduandos/as foram entrevistados/as para buscar compreender como interpretavam o currículo vivenciado por eles/as e que sentidos foram atribuídos a esse processo. Esses graduandos/as atuaram nos anos de 2017 e 2018, sendo que sete ainda participavam do Projeto na altura da entrevista e seis já haviam encerrado sua participação. Eles/as cursavam diferentes cursos e acompanhavam estudantes de diferentes anos escolares, como se pode ver no quadro a seguir. 


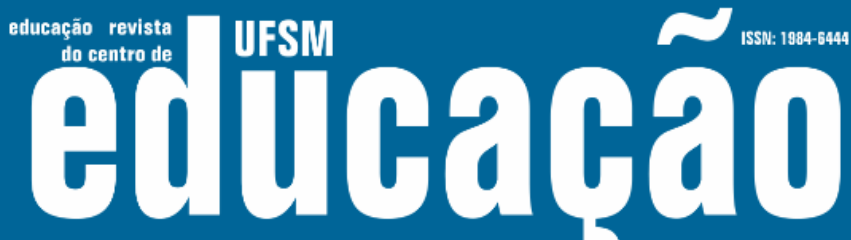

ISSN: 1984-6444 | http://dx.doi.org/10.5902/1984644445309

Quadro 1 - Distribuição dos/as graduandos/as por curso e estudante acompanhado

\begin{tabular}{|l|l|l|l|}
\hline Graduando/a $^{\mathbf{5}}$ & Curso & Aluno/a acompanhado & Diagnóstico \\
\hline Manuela & História & Maurício & Paralisia Cerebral \\
\hline Jéssica & Terapia Ocupacional & Pedro & $\begin{array}{l}\text { Transtorno do Espectro } \\
\text { Autista (TEA) }\end{array}$ \\
\hline Clara & Ciências Biológicas & Pedro & TEA \\
\hline Beatriz & Letras & Otávio & Síndrome de Down \\
\hline Fabiana & Geografia & Pedro & TEA \\
\hline Andrea & Matemática & Pedro & TEA \\
\hline Arthur & Artes Visuais & Júlio & Paralisia Cerebral \\
\hline Poliana & Dança & Fernanda & TEA \\
\hline Leandro & Ciências Biológicas & Pedro & TEA \\
\hline Andreza & Química & Júlio & Paralisia Cerebral \\
\hline Alexandre & Letras & Renan & TEA \\
\hline Juliana & Psicologia & Pedro/Rodrigo & TEA - TEA \\
\hline Rafael & Ciências Biológicas & Rodrigo & TEA \\
\hline
\end{tabular}

Fonte: elaborado pela autora, 2020.

Todos/as os/as graduandos/as atuaram por pelo menos seis meses junto a turmas em que havia estudantes PAEE. Além desses/as graduandos/as, outros/as também atuaram no Projeto, mas não foram entrevistados/as, seja porque não tiveram disponibilidade, seja porque tinham um tempo de atuação inferior a seis meses. A entrevista foi audiogravada, com autorização dos/as participantes e posteriormente transcrita. Em seguida, as entrevistas foram analisadas procurandose compreender os saberes e práticas acionados para a produção de professores/as que tomam a inclusão como aspecto central de suas subjetividades. A análise utilizou elementos da análise de discurso de inspiração foucaultiana (FOUCAULT, 1972), particularmente, a identificação das práticas de si e dos campos de saberes acionados pelos/as graduandos/as. Três aspectos emergiram centralmente: o questionar-se constantemente, a diferença na diferença e a crença no potencial de todos/as para aprender. É em torno deles que teço as análises do artigo. 


\section{Altharẫo}

ISSN: 1984-6444 | http://dx.doi.org/10.5902/1984644445309

\section{Saberes e práticas para a produção do/a docente inclusivo/a}

\section{O questionar (se) constante}

A inserção em uma escola de ensino fundamental que tem estudantes PAEE causa uma série de questionamentos nos/as graduandos/as. Logo, ao entrar em contato com a prática na escola, dúvidas, medos e ansiedade fazem parte das recordações dos/as graduandos/as e são narrados por eles/as de diversas formas. O "não-saber" aparece como uma marca desses primeiros dias e inicia um processo de questionamento das suas ações e da sua capacidade para lidar com as diferentes situações que aparecem, como se pode ver nos relatos a seguir:

De repente, eu caí de paraquedas aqui no CP. (Clara)

Quando saiu o resultado foi uma surpresa, né: "Consegui, e agora?". Veio a pergunta: "E agora?". Eu não tive contato, não sei como é, mas internalizei: "Vamos encarar o desafio". (Alexandre)

Mas eu achei muito jogado ao vento. Eu senti que quando eu entrei no início, eles falaram "Olha, você vai acompanhar alguém", mas não falaram o nome do aluno no dia. Falaram "Essas aqui vão ser suas orientadoras, amanhã vem aqui em tal horário para poder conversar com elas". [...] Foi uma coisa que para mim que fiquei pensando "Meu Deus, e agora?". (Rafael)

Cair de paraquedas, sentir-se "jogado ao vento", questionar-se "e agora?": essas falas dos/as graduandos/as remetem à sensação de não saber, de sentir-se perdido. A sensação de não ter aprendido o suficiente para lidar com a situação em que se encontram faz parte do processo inicial relatado por todos/as os/as graduandos/as entrevistados/as. Embora o saber seja considerado, na maior parte dos processos de ensino-aprendizagem, como essencial, parto aqui do princípio de que o "não saber" (ou pelo menos o não conhecer certos elementos teóricos) abre uma série de possibilidades para esses/as graduandos/as. Por não saberem, eles/as iniciam um processo de problematização de si mesmo e das práticas vivenciadas, o que possibilita a emergência de outros modos de ser e de relacionar-se com o outro. Partindo do princípio de que "não há ignorante que não saiba uma infinidade de coisas, e é sobre este saber, sobre esta capacidade em ato que todo ensino deve se 


\section{usm Autlbahat

ISSN: 1984-6444 | http://dx.doi.org/10.5902/1984644445309

fundar" (RANCIĖRE, 2005, p. 11), esses/as graduandos/as começam a construir seus caminhos, a questionar a si mesmo e construir-se de outro modo, como se vê no relato de um dos graduandos:

Eu... antes de entrar aqui, eu não tinha contato com ninguém de necessidade especial. A cara de pau me permite falar, mas eu não pensava muito sobre inclusão. Eu entrei aqui e tive contato com esse aluno. Isso me fez pensar sobre a inclusão desses alunos (Rafael)

O currículo do PID, centrado no contato com as práticas escolares e com os/as estudantes do ensino fundamental, proporciona uma reflexão sobre si mesmo e sobre os modos como se tem pensado à docência. Trata-se de um currículo em que "não se ensina explicitamente nada. Entretanto, se aprendem muitas coisas" (LARROSA, 1994, p. 45). Aprende-se a refletir sobre algo que ainda não havia sido pensado, a constituir-se de outro modo, a tornar-se um "professor reflexivo, capaz de examinar e reexaminar, regular e modificar constantemente, tanto sua própria prática quanto, sobretudo, a si mesmo, no contexto dessa prática profissional" (LARROSA, 1994, p. 49). Nesse sentido, os/as graduandos/as são levados a refletirem sobre si, sobre o seu próprio pensamento, seus processos educativos, em uma situação que modifica seus modos de ser. Esse questionamento amplia-se também para o questionamento de seus cursos de origem e para apontar saberes que consideram importantes para sua atuação como professores/as, como se percebe nos relatos a seguir:

\footnotetext{
Eu acho que essa formação fica muito deficiente né, porque eu fiz uma formação transversal na prática inclusiva e a professora pediu que a gente construísse uma aula que seja acessível a todos, que fosse inclusiva. Eu fiquei pensando: como vou adaptar uma aula de história para um aluno que fosse deficiente intelectual? Eu fiquei pensando no Maurício, com um aluno parecido com ele. Então como eu vou fazer isso? Eu não consegui. (Manuela)

O meu curso não tem uma disciplina voltada. Só tem LIBRAS, que é obrigatória para as licenciaturas. (Andreza)
}

Com exceção de uma graduanda ${ }^{6}$, todos/as os/as demais apontam que seus cursos de origem não deram acesso a saberes que eles/as consideram importantes 


\section{Authaดูã}

ISSN: 1984-6444 | http://dx.doi.org/10.5902/1984644445309

Eles/as precisam "conduzir suas condutas", a fim de tornarem-se professores/as inclusivos. Nesse processo, o reconhecimento da diferença aparece como aspecto central, como mostro a seguir.

\section{Aprender a respeitar a diferença na diferença}

A discussão a respeito da formação docente aponta que, apesar dos/as professores/as sentirem-se pouco preparados/as para lidar com estudantes com deficiência, quando se trata dos saberes relativos à inclusão, é possível afirmar que esses "não diferem de forma significativa dos saberes necessários para ensinar alunos sem deficiências, por serem saberes recomendados para qualquer professor que queira atender às necessidades de qualquer aluno" (NOZZI; VITALINO, 2017, p. 590). Parte-se do princípio de que o reconhecimento da diversidade dos/as estudantes e o princípio da heterogeneidade das salas de aula deve fazer parte da formação de todos/as os/as docentes, não havendo, então, necessidade de saberes específicos para lidar com estudantes PAEE. Embora esse seja um princípio válido, é importante reconhecer que as diferenças são inseridas em distintas relações de poder que fazem com que algumas sejam mais ou menos valorizadas que outras. Essas relações produzem sujeitos distintos em práticas que dividem, separam, incluem e excluem, definindo normalidades.

Problematizar as normas e perceber a diferença para além da ideia de diversidade comum a todos os seres humanos é um processo importante em práticas curriculares que se desenvolvem para a formação de professores/as que tomam a inclusão como aspecto fundamental de suas subjetividades. Os/as graduandos/as que vivenciaram o currículo do PID apontam a possibilidade de conviver com a diferença como um diferencial da formação produzida pelo Projeto. Assim, algo que se aprende nesse currículo refere-se ao "respeito à diferença", como mostram as falas a seguir: 


\section{$\sim$ ussm,

ISSN: 1984-6444 | http://dx.doi.org/10.5902/1984644445309

Eram crianças atípicas do que a gente vê em sala de aula. Tanto elas quanto o Maurício, a gente aprende a se comunicar com essas crianças. Você aprende que é preciso dar uma atenção, então, você aprende a respeitar essas diferenças (Manuela).

Na minha escola não era assim. Era todo mundo igualzinho, a escola era aquela coisa sem graça e tudo mais. Foi uma surpresa ver essa escola diferente daquilo que eu vivi. E foi bem legal! (Leandro)

Conhecer estudantes "diferentes" é tido como algo importante, já que a maioria dos/as graduandos/as não teve contato com estudantes PAEE durante sua formação como estudantes na educação básica e no ensino superior. Conviver com essa diferença faz com que eles/as se insiram na lógica de que é preciso "respeitar a diferença" e conviver com ela, considerando isso como positivo. Na lógica imposta pelo imperativo da inclusão, é necessário "alterar as práticas tradicionais, removendo as barreiras à aprendizagem e valorizando as diferenças dos alunos" (RODRIGUES, 2008, p. 11).

Todavia, é importante registrar que o respeito à diferença não é suficiente nesse processo. Afinal, como aponta Garcia (2013, p. 108), muitas vezes a lógica do respeito às diferenças faz com que se priorize "a convivência e sociabilidade entre os estudantes", deixando de "adotar como foco principal o trabalho com o conhecimento historicamente produzido e sistematizado na forma escolar". Além disso, a ideia de respeito pode levar à pouca problematização da diferença no ambiente escolar, já que se pode "exagerar a identidade do outro ou encerrá-la em pura diferença" (DUSCHATZKY; SKLIAR, 2011, p. 128). Porém, isso não parece ocorrer nas práticas narradas pelos/as graduandos/as que vivenciam o PID, pois eles/as procuram perceber "a diferença dentro da diferença". Procuram analisar, para além da norma que cerca determinada diferença e a nomeia como deficiência, e compreender cada um/a dos/as educandos/as. Assim, os/as graduandos/as têm a possibilidade de romper com certas noções que tinham em relação às deficiências, como se pode ver nos trechos a seguir: 
ISSN: 1984-6444 | http://dx.doi.org/10.5902/1984644445309

Acho que minha grande descoberta foi me deparar com uma criança autista com esse nível de interação social. Eu achei que eu ia chegar aqui e me deparar com uma criança que não conversava, e o Pedro é uma criança super comunicativa, que tem uma outra dinâmica (Jéssica)

Eu nem esperava isso dele, quando eu entrei. Eu pensava que todo autista era fechado, não era afetuoso, e ele me provou ao contrário. Quem não gosta do Pedro? " ${ }^{\text {risos }}{ }^{*}$. (Fabiana)

O que eu fiz com a Fernanda não vai funcionar com o Daniel da minha sala, não vai funcionar com o Pedro. Eles têm autismo, mas são personalidades, pessoas, individualidades, potencialidades, tudo muito diferente. (Poliana)

Compreender o/a estudante PAEE para além do diagnóstico que o marca como diferente e, sobretudo, como deficiente: esse parece ser um aprendizado importante nesse processo. Se, muitas vezes, os/as autistas são narrados/as como pessoas quietas, introspectivas, caladas, o contato com diferentes estudantes que são nomeados/as como autistas permite percebê-los/as para além desse recorte. Os/as monitores/as passam a compreender que o grupo de sujeitos que integra o espectro do autismo "apresenta diferenças importantes entre si em termos de cognição, grau de interação social, condições de autocuidado, demanda de acompanhamento interdisciplinar, dentre outros pontos" (RAHME, 2018, p. 219). A convivência cotidiana com o autismo (e também com outras diferenças que são nomeadas como deficiência) permite compreendê-lo como "algo inerente ao humano e que expressa a diversidade da vida" (BORGES; WERNER, 2018, p. 15). currículo do PID possibilita a compreensão das diferenças e a problematização do modo como algumas são consideradas como limitadoras. Isso contribui de forma significativa para que mais uma das aprendizagens desse currículo efetive-se: a crença na potencialidade de todos/as para aprender.

\section{Todos/as podem aprender}

No processo de reconhecer a diferença, entender a potencialidade de todos/as para aprender emerge como aspecto central. Se, historicamente, as pessoas com deficiência foram consideradas como menos capazes, a convivência diária proporcionada pelo currículo do PID leva a outra concepção. Assim, um aprendizado importante para os/as futuros/as docentes refere-se à crença na 


\section{Autharẫ}

ISSN: 1984-6444 | http://dx.doi.org/10.5902/1984644445309

potencialidade de todos/as para aprender, sem subestimá-los/as, como se vê nos excertos a seguir:

e principalmente a não subestimar porque muitas vezes você chega pensando que essas crianças não vão dar conta de fazer nada e eles dão muito mais conta do que você pensa. (Manuela)

O Pedro sempre acertava o joguinho, quando ia para o quadro. Eu até duvidava, mas ele chegava lá... eu acho que a memória dele, o aprendizado... muito impressionante (Fabiana)

A percepção da singularidade de cada um/a, que não descaracteriza a possibilidade de aprender, emerge nas falas dos/as graduandos/as e caracteriza-se como uma problematização dos modos como a escola e as relações de ensinaraprender processam-se nesse espaço. Se considerarmos que a escola foi criada na Modernidade com uma lógica de um padrão único de aprender, a inserção de estudantes PAEE demanda uma mudança. Afinal, ao mesmo tempo em que a educação é um direito de todos/as, cada um/a necessita de um estilo diferente para aprender. Todos/as têm potencialidade, desde que se modifique o padrão do que se quer ensinar e do como isso pode ser feito.

Mantoan e Lima (2017, p. 828) afirmam que "o entendimento da inclusão sob a égide da diferença revolve o que se entende por ensinar e aprender". O aprender "refere-se aos atos subjetivos (pessoais) operados pelo estudante frente a um contexto" (ibidem). Já o ensinar "envolve encontro, não é fortuito, apesar da impossibilidade de previsão, controle e/ou mensuração do que pode acontecer" (ibidem). Nesse processo, aprender não necessariamente relaciona-se com os saberes e conhecimentos tradicionais e ensinar não concerne à transmissão desses conhecimentos. Aprender e ensinar referem-se ao encontro, à potência do contato com o outro, à capacidade de abrir-se para outras potencialidades. Na interação que se estabelece com estudantes PAEE, os/as graduandos/as têm a possibilidade de criar outros modos de ensinar-aprender, que não passam pelos padrões unificados. Um aspecto destacado por eles/as, refere-se ao reconhecimento daquilo que a criança já sabe, articulado às potencialidades dos cursos de origem de cada graduando/a. A monitora Poliana, que cursava Licenciatura em Dança, tece 


\title{
$\sim$ ussm,

ISSN: 1984-6444 | http://dx.doi.org/10.5902/1984644445309

comentários sobre como pode articular saberes de seu curso às demandas e às potencialidades da estudante acompanhada:

\begin{abstract}
E eu acho que para trabalhar em cima disso, a gente primeiro tem que trabalhar quem é essa criança. O que essa criança gosta, observar mesmo o que ela tem de potencial, para trabalhar em cima disso. Porque a gente sabe que o autismo, ele sempre tem um âmbito que é mais forte. A Fernanda era muito boa em português. O que eu podia trazer para estimular ela? Por exemplo, através da dança mesmo eu trouxe muito da alfabetização. Então, eu levei essa questão da dança, do movimento para ensinar ela a ler, para escrever letra cursiva, que tinha um pouco de dificuldade. (Poliana)
\end{abstract}

Reconhecer os eixos de interesse das crianças emerge como um aspecto importante para promover o aprender. Poliana relata como a percepção da criança como indivíduo é fundamental no processo escolar. Nesse sentido, ela se movimenta para "olhar para o aprendiz e compreendê-lo como um sujeito que aprende e promover condições para que ele se expresse a sua maneira" (ORRÚ, 2019 , p. 171). A dança aparece como algo capaz de auxiliá-la naquilo que já era eixo de interesse da criança e promover, assim, outros sentidos para o aprender. Nesse processo, pensar em um tempo que se dá para além do cronológico e que envolve outras dimensões também emerge como fundamental:

Eu aprendi muito essa questão de respeitar o tempo da criança. Porque é muito difícil em uma escola você respeitar o tempo de todos em uma turma com 25 alunos. Essa questão de entender as particularidades de cada um. (Poliana)

Em um currículo de formação docente que se centra na vivência cotidiana na escola, algumas práticas são destacadas como constituidoras de outro modo de pensar. A vivência de um tempo escolar, nomeado como Grupo de Trabalho Diferenciado, que tinha como tema "Dança e potencialidades", emergiu na fala de quase todos/as os/as graduandos/as como algo que os/as modificou sobremaneira. Assim, eles/as relatam que 


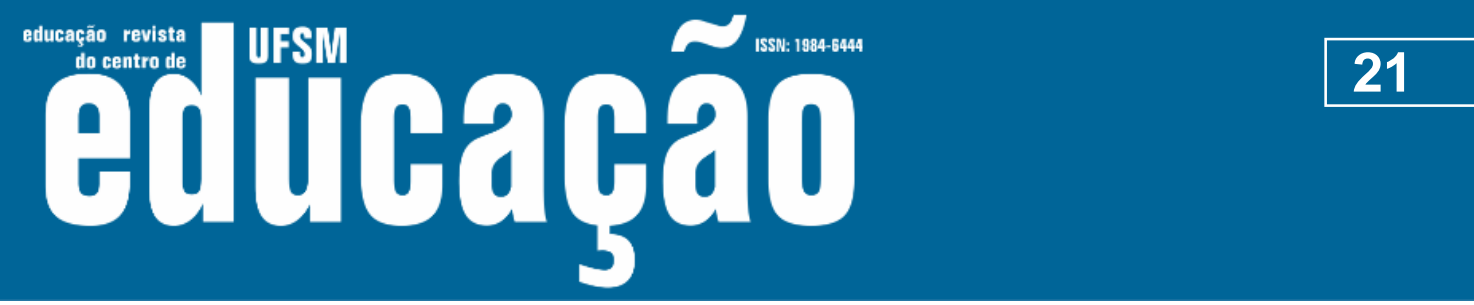

ISSN: 1984-6444 | http://dx.doi.org/10.5902/1984644445309

Foi uma experiência incrível porque eram muitos alunos diferentes, muitos alunos com deficiências diferentes. O Maurício, o Júlio, que são alunos que não tem uma comunicação oral e é difícil entender o universo deles, o que eles estão pensando, o que eles estão querendo. Eu vi que a Lorena [professora do GTD] desenvolve de um jeito que você nem entende e é maravilhoso. (Manuela)

Foi muito legal, foi muito emocionante o final, e ver, por exemplo, o Júlio no início do ano quando ele fazia o GTD, e agora. Ele criou um pedaço da dança sozinho com os meninos. Às vezes ele chegava muito nervoso no GTD e começava a rolar a música e ele ficava tranquilo. A questão motora dele melhorou demais, ele consegue sentar sem apoio de tronco, eu acho muito legal, a interação dos meninos. (Jéssica)

Quando questionados, durante a entrevista, sobre qual o momento mais marcante de sua formação, grande parte dos/as monitores/as relatou a vivência nesse GTD como aquilo que mais os/as tocou. A possibilidade de interação entre estudantes PAEE, estudantes neurotípicos/as, monitores/as de diferentes graduações e professora mais experiente foi narrada como possibilitadora de entender a diferença a partir de outra perspectiva. Parece que, nessa prática, a não hierarquia entre as inteligências aparecia como algo marcante que abria outras possibilidades para o aprender. Mantoan e Lima (2017, p. 830) afirmam que "não havendo hierarquia entre inteligências, uma concepção de sujeito inacabado, descentrado e singular, capaz de aprender a seu tempo e modo peculiares é fundamental". Parece que a vivência nesse GTD possibilitou pensar para além dos cursos de origem e ver a potencialidade de todos/as para aprender a criar, incluindo os/as próprios/as graduandos/as que também se perceberam como capazes de produzir um espetáculo.

No início eu fiquei preocupada por apresentar na frente de um público, mas à medida que eu ia acompanhando as aulas, eu percebi que era uma coisa muito tranquila. Os meninos adoravam o GTD de dança. Era um momento ótimo, porque eu não interagia só com o Otávio, eu interagia com todos os meninos que participavam, e também os outros monitores. (Beatriz)

Foi maravilhosa, eu achei muito lindo. No dia do espetáculo eu chorei demais. A gente vê os meninos e pensa que não vai dar certo, porque é a mesma coisa na turma, chegou lá no dia e os meninos surpreenderam, foi muito tranquilo. (Andrea) 


\section{Autharão}

ISSN: 1984-6444 | http://dx.doi.org/10.5902/1984644445309

Colocar-se na posição de não saber e acreditar em sua própria potencialidade para aprender parece ser também algo produzido por esse currículo. Assim, além de verem que os/as estudantes PAEE podem fazer algo que, a princípio, não era esperado para eles/as, os/as graduandos/as também sentem que eles/as mesmos/as são capazes de produzir algo que não imaginavam antes, como uma produção artística. Letras, Química, Matemática, Ciências Biológicas, Terapia Ocupacional, Dança entram em um processo de "desierarquização" dos saberes e os/as graduandos/as, assim como os/as estudantes PAEE, deixam de ser fixados a suas áreas de formação e passam a ser sujeitos inacabados, sempre abertos ao aprender. Passam a ser "seres únicos e singulares que se diferenciam e se multiplicam" (MANTOAN; LIMA, 2017, p. 831), produzindo novos modos de ser e estar em um currículo de formação docente que se produz em uma escola de ensino fundamental.

\section{Considerações finais: para além do imperativo da inclusão}

Argumentei, neste artigo, que a vivência de um currículo de formação inicial docente que se centra na inserção em uma escola de ensino fundamental que tem estudantes PAEE reativa aquilo que vem sendo nomeado como imperativo da inclusão. Esse conceito - tal como tem sido utilizado por autores/as que utilizam ideias foucaultianas para pensar a educação inclusiva - pode ser compreendido como um modo de exercer poder na contemporaneidade, que determina a inclusão compulsória de todos/as os/as estudantes na escola comum. Ao problematizar esse princípio, a ideia de imperativo da inclusão pode ser compreendida como um movimento contrário à inserção de estudantes PAEE na escola comum. É importante registrar que não se trata disso. Como apontam Lopes e Fabris (2017, p. 25), "por mais críticas que façamos à inclusão e à forma como ela vem se estabelecendo como um imperativo político do Estado Brasileiro [...] ela é uma forma de ação otimista sobre nós mesmos". As autoras defendem que outros sentidos podem ser construídos a partir da inclusão dos/as estudantes PAEE e que é 


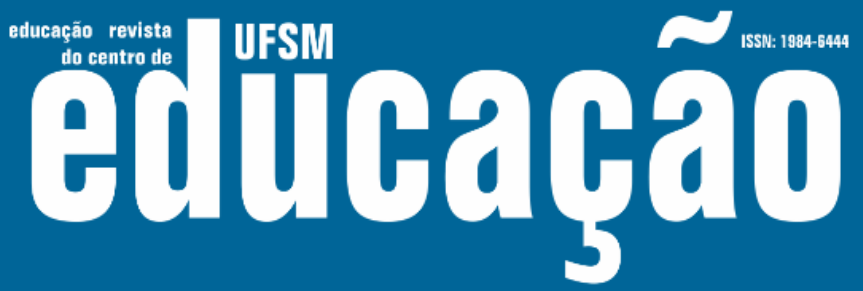

ISSN: 1984-6444 | http://dx.doi.org/10.5902/1984644445309

necessário problematizá-los constantemente, justamente com o objetivo de manter sua potência para repensar a escola.

A análise dos sentidos atribuídos pelos/as graduandos/as à formação proporcionada pelo PID evidencia a potencialidade de um currículo que se centra no contato com a diferença, na prática imersiva na escola de educação básica e na vivência de experiências que ultrapassam os saberes tradicionais da formação docente. Os/as estudantes mostram que puderam exercer sobre si mesmos/as determinadas práticas que podem auxiliar a formá-los/as como docentes mais sensíveis e abertos à diferença na prática escolar.

Esse processo de constituição de si mesmos/as como docentes inclusivos/as não se dá sem questionamentos. A prática inclusiva na escola investigada não deixa de ser criticada pelos/as graduandos/as, que percebem suas limitações. Alguns/algumas estudantes registram o cansaço advindo do contato constante com os/as educandos/as PAEE, o processo de responsabilização que sentem pelos sucessos e fracassos desses/as estudantes, o despreparo do corpo docente da instituição para lidar com a inclusão, a falta de estrutura física acessível na escola pesquisada. Contudo, também destacam a potencialidade desse espaço que possibilita para eles/as um novo modo de ver a escola, a prática docente e a inclusão. Nesse sentido, esse currículo possibilita que esses/as estudantes possam pensar a si e à educação de outra maneira. Eles/as se colocam como indivíduos que, "na trama das relações de poder que os atravessam, podem perceber outras coisas, diferentemente daquelas que estão percebendo; [...] ser de outra forma, diferentemente de como estão sendo" (KOHAN, 2003, p. 89). Produzem-se, assim, como futuros/as professores/as que veem a potencialidade da educação inclusiva e que tentam construí-la nos diferentes momentos por eles/as vivenciados.

\section{Referências}

ANDRADE, Sandra. A entrevista narrativa ressignificada nas pesquisas educacionais pós-estruturalistas. In: PARAíSO, Marlucy; MEYER, Dagmar. (Org.). Metodologias pós-críticas de pesquisas em Educação. Belo Horizonte: Mazza Edições, 2012. 


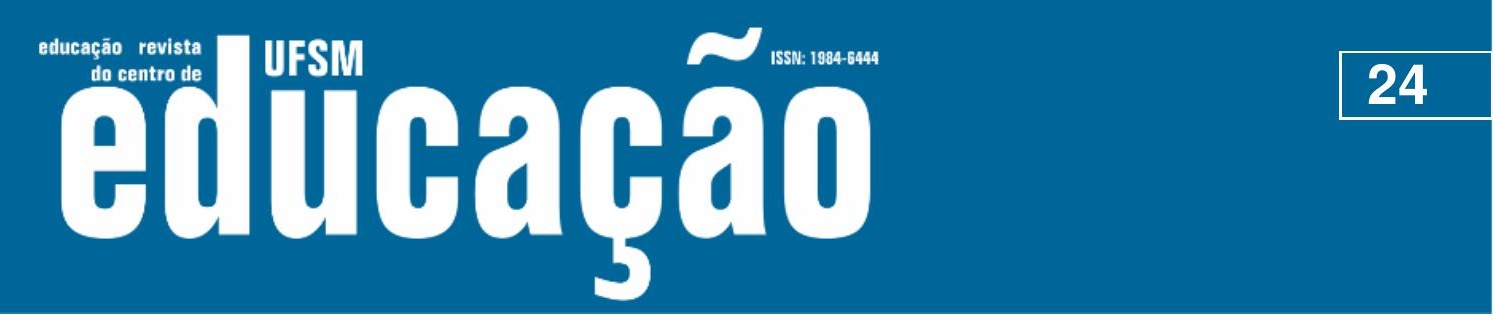

ISSN: 1984-6444 | http://dx.doi.org/10.5902/1984644445309

BORGES; Adriana Araújo Pereira; WERNER, Andréa. Em busca do tempo perdido: a reviravolta das mães autistas. In: BORGES, Adriana Araújo Pereira; NOGUEIRA, Maria Luísa Magalhães. $O$ aluno com autismo na escola. Campinas: Mercado de Letras, 2018.

BRASIL. Lei de Diretrizes e Bases da Educação Nacional. Brasília: MEC, 1996. Disponível em http://www.planalto.gov.br/ccivil_03/LEIS/L9394.htm. Acesso em: 15 jul. 2018.

CARVALHO, Alexandre Filordi de; GALLO, Silvio D. de Oliveira. Foucault e a governamentalidade democrática: a questão da precarização da educação inclusiva. Mnemosine, Rio de Janeiro, v.16, n.1, p. 146-160, 2020.

CORAZZA, Sandra. O que quer um currículo: pesquisas pós-críticas em educação. Petrópolis: Vozes, 2001.

CORAZZA, Sandra. Diferença pura de um pós-currículo. In: LOPES, Alice. MACEDO, Elizabeth. Currículo: debates contemporâneos. São Paulo: Cortez, 2005.

DELEUZE, Gilles. Foucault. São Paulo: Brasiliense, 1988.

DREYFYS Hubert; RABINOW, Paul. Michel Foucault: Uma trajetória filosófica para além do estruturalismo e da hermenêutica. Rio de Janeiro: Forense, 1995.

DUSCGATZKY, Silvia; SKLIAR, Carlos. O nome dos outros. Narrando a alteridade na cultura e na educação. In: LARROSA, Jorge; SKLIAR, Carlos (orgs.) Habitantes de Babel. Belo Horizonte: Autêntica, 2011, p. 119-138.

FARIA, Juliana Batista; DINIZ-PEREIRA, Júlio Emílio. Residência pedagógica: afinal, o que é isso? Revista de Educação Pública, Cuiabá, v.28, n. 68, p. 33-356, mai./ago. 2019.

FARIA, Juliana Batista. O naufrágio, o baile e a narrativa de uma pesquisa: experiências de formação de sujeitos em imersão docente. 2018. 385f. Tese de Doutorado em Educação, Belo Horizonte, Universidade Federal de Minas Gerais, 2018.

FOUCAULT, Michel Arqueologia do saber. Petrópolis: Vozes, 1972.

FOUCAULT, Michel. Crise da medicina ou crise da antimedicina. Verve, São Paulo, v. 18, p. 167-194, 2010.

FOUCAULT, Michel. História da Sexualidade II: o uso dos prazeres. São Paulo: Graal, 1998. 


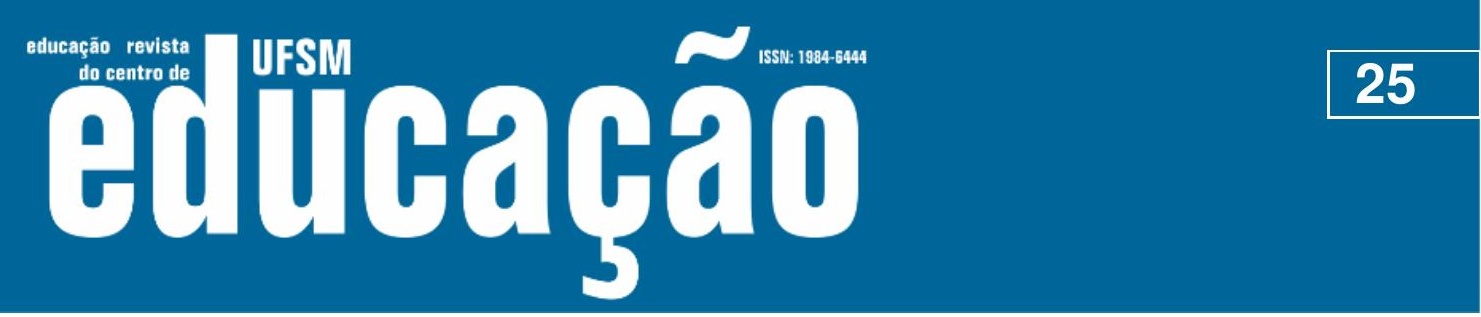

ISSN: 1984-6444 | http://dx.doi.org/10.5902/1984644445309

FOUCAULT, Michel. Soberania e disciplina. In: MACHADO, Roberto. Microfísica do poder. Rio de Janeiro: Graal, 2000. p. 179-191.

FOUCAULT, Michel. Verdade e subjetividade. Revista de Comunicação e Linguagem, Lisboa, n. 19, p. 203-223, 1993.

GALLO, Sílvio. Biopolítica e subjetividade: resistência?. Educar em Revista, Curitiba, n. 66, p. 77-94, dezembro de 2017. Disponível em: http://www.scielo.br/scielo.php?script=sci_arttextpid=S0104-

40602017000400077 Ing=ennrm=iso. Acesso em: 05 de janeiro de 2021.

GARCIA, Rosalba Maria Cardoso. Política de educação especial na perspectiva inclusiva e a formação docente no Brasil. Revista Brasileira de Educação, Rio de Janeiro, v. 18, n. 52, p. 101-119, Mar. 2013. Disponível em: http://www.scielo.br/scielo.php?script=sci_arttext\&pid=S1413-

$24782013000100007 \&$ Ing=en\&nrm=iso. Acesso em: 28 de mai. de 2020.

KASSAR, Mônica de Carvalho Magalhães. A formação de professores para a educação inclusiva e os possíveis impactos na escolarização de alunos com deficiências. Cadernos CEDES, Campinas, v. 34, n. 93, p. 207-224, mai. 2014. Disponível em: http://www.scielo.br/scielo.php?script=sci_arttext\&pid=S0101 $32622014000200207 \&$ Ing=en\&nrm=iso. Acesso em: 28 de mai. de 2020.

KOHAN, Walter. Infância. Entre Educação e Filosofia. Belo Horizonte: Autêntica, 2003.

LARROSA, Jorge. Tecnologias do eu e educação. In: SILVA, Tomaz Tadeu (Org). O sujeito da educação: estudos foucaultianos. Petrópolis: Vozes, 1994.

LOCKMANN, Kamila. As reconfigurações do imperativo da inclusão no contexto de uma governamentalidade neoliberal conservadora. Pedagogía y Saberes, Colômbia n. 52.20 p. 67-75. 2020. Disponível em: https://www.researchgate.net/publication/339073586_As_reconfiguracoes_do_imper ativo_da_inclusao_no_contexto_de_uma_governamentalidade_neoliberal_conserva dora Acesso em: 05 de jan. de $202 \overline{1}$.

LOPES, Maura Corcini. Políticas de Inclusão e Governamentalidade. Educação e Realidade, Porto Alegre, vol. 34, n. 2, pp. 153-169. mai/ago. 2009

LOPES, Maura Corcini. FABRIS, Eli Henn. Inclusão \& educação. Belo Horizonte: Autêntica, 2017.

LOPES, Maura Corcini; MORGENSTERN, Juliane Marschall. Inclusão como matriz de experiência. Pro-Posições, Campinas, v. 25, n. 2, p. 177-193, ago. 2014. Disponível em: http://www.scielo.br/scielo.php?script=sci_arttext\&pid=S0103$73072014000200010 \&$ Ing=en\&nrm=iso. Acesso em: 28 de mai. de 2020. 


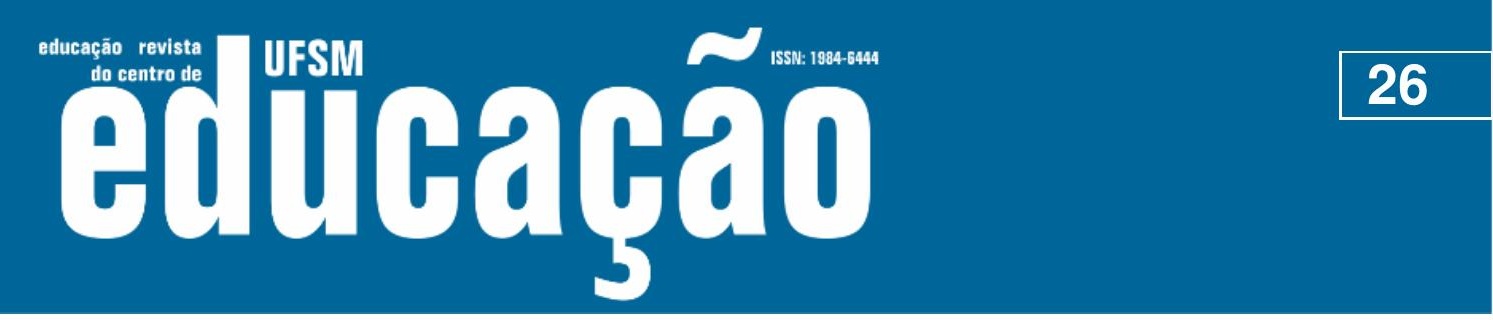

ISSN: 1984-6444 | http://dx.doi.org/10.5902/1984644445309

LOPES, Maura Corcini; VEIGA-NETO, Alfredo. inclusão, exclusão, in/exclusão. Verve, São Paulo, v. 20, 2011.

MANTOAN, Maria Teresa Egler. Inclusão Escolar: O que é? Por quê? Como fazer? São Paulo: Moderna, 2009.

MANTOAN, Maria Teresa Egler; LIMA, Norma Silva Trindade de. Notas sobre inclusão, escola e diferença. ETD - Educação Temática Digital, Campinas, v. 19, n. 4. p. 824-832.

MOREIRA. Adriana Belmonte. Terapia Ocupacional: história crítica e estratégias. Vita et Sanitas, Trindade/Go, v. 2, n . 02, 2008.

NOZZI, Gislaine; VITALINO, Celia Regina. Saberes de professores propícios à inclusão dos alunos com necessidades educacionais especiais: condições para sua construção. Revista Educação Especial, Santa Maria, v. 30, n. 59, set./dez. 2017, p. 589-602.

ORRU, Sílvia Ester. Aprendizes com autismo: aprendizagens por eixos de interesse em espaços não excludentes. Petrópolis: Vozes, 2019.

PARAÍSO, Marlucy Alves. Currículo e mídia educativa brasileira: poder, saber, subjetivação. Chapecó-SC: Editora Argos, 2007.

RAHME, Mônica Maria Farid. A função da mediação na trajetória de um aluno com Transtorno do Espectro Autista no Ensino Fundamental. In: BORGES, Adriana Araújo Pereira; NOGUEIRA, Maria Luísa Magalhães. O aluno com autismo na escola. Campinas: Mercado de Letras, 2018. p. 291-313.

RANCIÈRE, Jacques. O mestre ignorante: cinco lições sobre a emancipação intelectual. Belo Horizonte: Autêntica, 2005.

RODRIGUES, David. Desenvolver a Educação Inclusiva: dimensões do desenvolvimento profissional. 2008. Inclusão Revista da Educação Especial, Brasília/Secretaria de Educação Especial/MEB, v. 4, n. 2, p. 7-16 jul./out. 2008.

SILVA, Tomaz Tadeu. Currículo e identidade social: territórios contestados. In: SILVA, Tomaz Tadeu. Alienígenas na sala de aula: uma introdução aos Estudos Culturais em Educação. Petrópolis: Vozes, 1995.

SOUTO, Kely Cristina Nogueira; ESTEVES, Manuela. O processo de formação de professores da educação básica no interior de uma escola de ensino fundamental: o olhar dos graduandos sobre o ser professor e a prática profissional. Revista IberoAmericana de Estudos em Educação, Araraquara/SP, v. 11, n. esp. 3, p.1587-1601, 2016. 


\title{
N

ISSN: 1984-6444 | http://dx.doi.org/10.5902/1984644445309

TEIXEIRA, Inês A. de Castro; PÁDUA, Karla Cunha. Virtualidades e Alcances da Entrevista Narrativa. In: CONGRESSO INTERNACIONAL SOBRE PESQUISA (AUTO) BIOGRÁFICA, II, 2006, Salvador. Anais ... Salvador: UNEB, 2006. 1 CDROM.

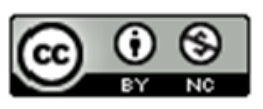

This work is licensed under a Creative Commons Attribution-NonCommercial 4.0 International (CC BY-NC 4.0)

\section{Notas}

\begin{abstract}
${ }^{1}$ Os Colégios de Aplicação são escolas de educação infantil, ensino fundamental e ensino médio vinculadas às Universidades Federais brasileiras. Atualmente, são 16 Colégios no Brasil, em diferentes estados do País. A fim de evitar a quebra de anonimato, o Colégio não foi identificado neste artigo.

2 Este artigo é parte da pesquisa "Inclusão na Escola Regular de Tempo Integral: principais desafios para o cotidiano escolar e para a formação docente". A referida pesquisa foi submetida ao Comitê de Ética em Pesquisa e aprovada em 20 de outubro de 2017, número do Projeto: CAAE 76795417.0.0000.5149.

3 Utilizo a expressão "capacitação" por ser ela que está presente na legislação supracitada. Além disso, Kassar (2014) mostra como os Programas de Formação Governamentais e as políticas nacionais voltadas à inclusão criaram uma cisão no que se refere aos/às docentes para atuar na educação inclusiva. Há os especializados (aqueles que se formaram especificamente em educação especial) e os capacitados (docentes da classe regular em que há estudantes PAEE incluídos e que devem ter em sua formação inicial conteúdos relativos à inclusão).
\end{abstract}

${ }^{4} \mathrm{Na}$ perspectiva aqui adotada, governamento ou governo é compreendido como entendido como a "ação sobre a ação, sobre ações eventuais, ou atuais, futuras ou presentes" (DREYFUS; RABINOW, 1995, p. 243).

5 Os nomes são fictícios, conforme acordo realizado com os/as estudantes no momento das entrevistas.

${ }^{6}$ Essa graduanda cursava Terapia Ocupacional (TO), curso que visa a formação de um profissional da área da saúde que, tradicionalmente, atue no campo da reabilitação. A grade do Curso ofertada pela universidade pesquisada é composta por 6 disciplinas que abordam deficiências. Apesar de ofertar uma extensa base sobre esses fenômenos, o curso de TO não aborda práticas na área escolar, isto é, não é voltado para a formação docente, se voltando mais para questões socioeducativas, infantis e hospitalares. 